\title{
Histopathological phenotypes of early gastric cancer and its background mucosa
}

\author{
Yasuyuki Kudo ${ }^{1,2}$, Satoko Morohashi ${ }^{1}$, Kaori Takasugi, ${ }^{1,2}$, Shinji Tsutsumi ${ }^{1,3}$, Hiroshi Ogasawara ${ }^{1,3}$, Norihiro \\ Hanabata $^{2}$, Tetsuro Yoshimura ${ }^{2}$, Fuyuki Sato ${ }^{1}$, Shinsaku Fukuda ${ }^{2}$, and Hiroshi Kijima ${ }^{1}$ \\ Departments of ${ }^{1}$ Pathology and Bioscience, ${ }^{2}$ Gastroenterology and Hematology, and ${ }^{3}$ Surgery, Hirosaki University Graduates School of \\ Medicine, 5 Zaifu-cho, Hirosaki, Aomori 036-8562, Japan
}

(Received 26 December 2010; and accepted 7 January 2011)

\begin{abstract}
Recent advances in endoscopic submucosal dissection (ESD) techniques contribute to endoscopic treatment of early gastric cancer (EGC). Recognition of chronic atrophic gastritis as the background is important for high-quality detection and diagnosis of EGC. But, relationships between EGC and atrophy of the background gastric mucosa caused by Helicobacter pylori are not well understood. The present study demonstrated histopathological phenotypes of EGC, as well as chronic atrophic gastritis as background mucosa of EGC. We evaluated mucosal heights, number of glands, and degree of intestinal metaplasia (IM) of the background gastric mucosa, using 81 cases of EGC resected by ESD. Gastric phenotype cancer cases showed IM of the background gastric mucosa less frequently, compared with intestinal phenotype cancer cases (score of IM, 1.15 vs. $1.65, P=0.012$ ). The average mucosal heights around EGC were lower in moderately to poorly differentiated adenocarcinoma cases than well differentiated adenocarcinoma cases $(442.6 \mu \mathrm{m}$ vs. $500.2 \mu \mathrm{m}, P=0.011$ ). The mucosal atrophy indicated by average heights of background mucosa was low in the gastric phenotype cancer cases, compared with the intestinal phenotype cancer cases $(452.8 \mu \mathrm{m}$ vs. $505.6 \mu \mathrm{m}, P=0.018)$. In the fundic gland area, the mucosal heights were low in the gastric phenotype cancer cases, compared with the intestinal phenotype cancer cases (413.2 $\mu \mathrm{m}$ vs. $495.5 \mu \mathrm{m}, P=0.015)$. Our results using EGC specimens indicated that gastric phenotype cancer and moderately to poorly differentiated adenocarcinoma had atrophic background mucosa with lower mucosal heights and less IM. The atrophic gastric mucosa with less IM is thought to play an important role in gastric carcinogenesis, especially tumoriogenesis of gastricphenotype cancer.
\end{abstract}

Recently, due to advances in techniques for diagnosing gastric cancer, such as endoscopy and development of narrow band imaging (NBI), the number of patients diagnosed with early gastric cancer (EGC) has been increased both in Japan and elsewhere (8, $12,14)$. It is very important to detect EGC and to

Address correspondence to: Hiroshi Kijima, MD, Department of Pathology and Bioscience, Hirosaki University Graduates School of Medicine, 5 Zaifu-cho, Hirosaki, Aomori, 036-8562, Japan

Tel: +81-172-39-5029, Fax: +81-172-39-5030

E-mail: hkijima@cc.hirosaki-u.ac.jp make its preoperative diagnosis, because endoscopic therapy or surgical treatment after the early detection can result in better prognosis of gastric cancer (14). In the field of endoscopic therapy, endoscopic mucosal resection (EMR) focuses on only smallsized EGC, but advances in endoscopic submucosal dissection (ESD) are able to treat large EGC. EGC is histopathologically classified into two types, i.e. "intestinal type" composed of well differentiated adenocarcinoma, and "diffuse type" composed of undifferentiated carcinoma (actually poorly differentiated adenocarcinoma and/or signet-ring cell carcinoma), based on the tendency of gland formation (7, 
11, 20). The "intestinal type" tumors have been considered to arise from gastric mucosa with intestinal metaplasia (IM) and the "diffuse type" tumors from gastric mucosa without IM. It has been suggested that these two tumor types involve distinct pathways of the gastric carcinogenesis $(19,20,23)$.

Chronic atrophic gastritis is caused mainly by $\mathrm{He}$ licobacter pylori infection. Gastric mucosal atrophy defined as loss of mucosal glands leads to thinning of the mucosa, and is a common denominator in all pathological processes, causing severe mucosal damage. In addition, IM is common in chronic gastritis infected with Helicobacter pylori. Therefore, scoring of the Updated Sydney System includes the mucosal atrophy and IM, in addition to inflammatory cell infiltration (2).

The risk of developing gastric cancer is related to chronic active inflammation with Helicobacter pylori $(17,22)$. Previous studies have suggested that some types of IM provide important information regarding the risks of gastric cancer (15). IM is thought to be one of the precancerous lesions in the multiple progression of gastric carcinoma as proposed by Correa (1). However, the relationship of EGC and atrophic mucosa without IM are not well understood.

In this study, we evaluated gastric atrophy using mucosal heights, number of glands and score of IM, and relationships between EGC and its background atrophic mucosa.

\section{MATERIALS AND METHODS}

Patient materials and tissue sampling. We analyzed 81 EGC cases resected by endoscopic submucosal resection (ESD) and filed in Hirosaki University Hospital and Seihoku Chuo Hospital. The clinicopathological data of the cases are summarized in Table 1. The histological classification is based on the Japanese Classification of Gastric Carcinoma (4). EGC tissue specimens resected by ESD were pasted on the cork boards on equal force stretched, routinely fixed with $10 \%$ buffered formalin and examined carefully at macroscopic levels. These specimens were serially cut in 2 mm-width, embedded in paraffin, thin-sectioned, and stained with hematoxylin and eosin $(\mathrm{H} \& \mathrm{E})$. After examination of the H\&E sections, histological mapping of the cancer tissue was performed on color prints. Several representative tissue sections in each case were selected for histochemistry and immunohistochemistry of mucin phenotypic analysis. Paraffin blocks corresponding to the selected H\&E sections were cut into $4 \mu \mathrm{m}$ consecutive sections for histochemical and immuno-
Table 1 Clinicopathological features of early gastric cancer

\begin{tabular}{lc}
\hline & $\mathrm{n}=81$ \\
\hline Age (mean \pm s.d.) & $72.2 \pm 7.9$ \\
Sex & 51 \\
$\quad$ Male & 30 \\
$\quad$ Female & \\
Location & 38 \\
$\quad$ Pyloric glands area & 41 \\
$\quad$ Fundic glands area & 2 \\
$\quad$ Cardiac glands area & \\
Macroscopic type & 59 \\
$\quad$ Elevated & 22 \\
$\quad$ Depressive & \\
Histopathological grade & 53 \\
$\quad$ Well differentiated & 23 \\
$\quad$ Moderately differentiated & 5 \\
$\quad$ Poorly differentiated & \\
Depth of invasion & 61 \\
Intramucosal & 20 \\
$\quad$ Submucosal &
\end{tabular}

histochemical staining.

Histopathological and immunohistochemical examinations. Immunohistochemical examination was performed on deparaffinized sections using the standard avidin-biotin-peroxidase complex (ABC) method with an automated immunostainer (Benchmark XT; Ventana Medical System, Tucson, AZ, USA). The antibodies used are listed in Table 2. Both cytoplasmic and luminal membranous immunoreactivities were judged as positive for human gastric mucin (HGM) and CD10, and cytoplasmic immunoreactivity as positive for MUC5AC, MUC6 and MUC2. HGM, MUC5AC, MUC6 and MUC2 are extracellular secreted mucins. The mucins are high-molecular weight glycoproteins and widely distributed in areodigestive and genital organs, and are associated with cell-to-cell adhesion, cell migration including tumor metastasis, and immunological defense. CD10 is expressed on the surface of a variety of normal and neoplastic cells, and is highly detected on immature B lympocytes, intestinal brush borders, and renal epithelial cells. CD10 is reactive predominantly at the cell membrane, while the mucins react predominantly in the cytoplasm. CDX2, a caudal-related homeobox gene, is a regulatory factor for intestinal development and differentiation of goblet cells. Increased CDX2 expression is seen in intestinal type cancers, and may play a role in gastric carcinogenesis. 
Table 2 Immunohistochemical staining for gastric and intestinal phenotypes

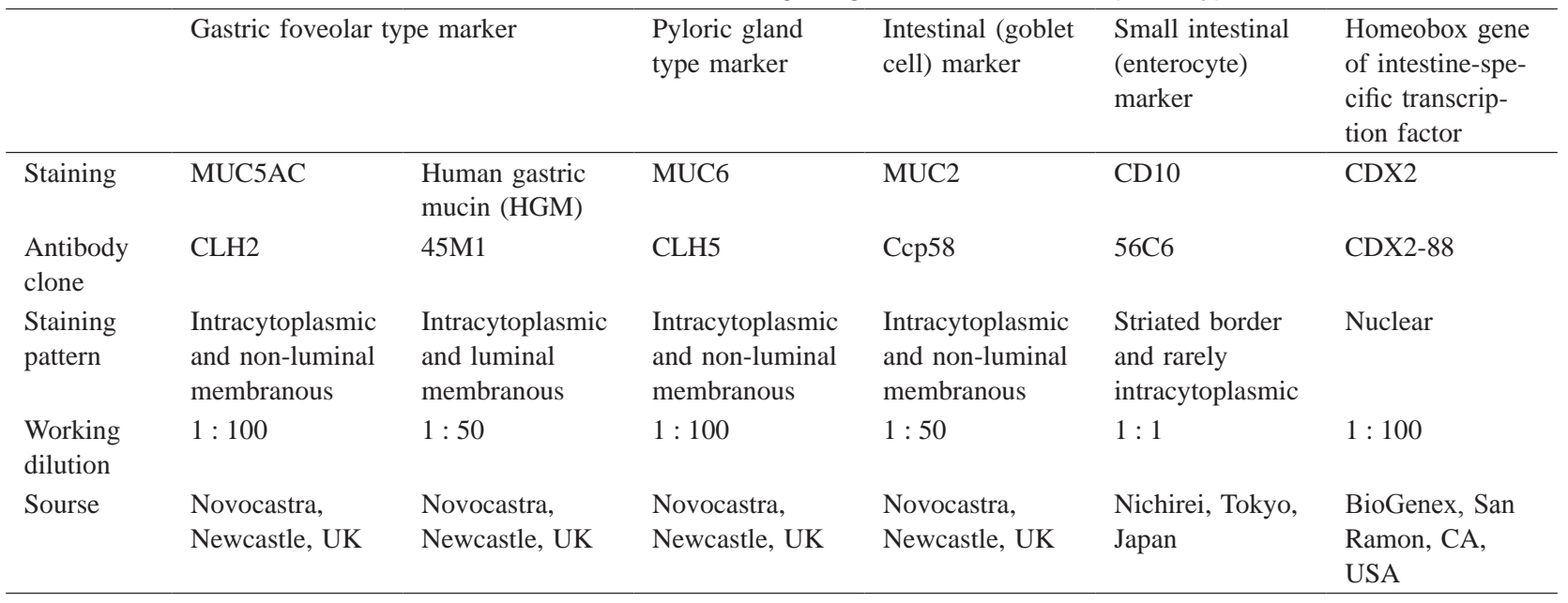

Definition of mucin phenotypes of carcinomas. The presence of reactive cells was semi-quantitatively estimated according to the percentage of stained cells within the totally stained sections. The gastric phenotype was judged by the positive reaction of HGM, MUC5AC and/or MUC6 reactive cells (Fig. 1). Gastric phenotypic cancers with MUC2 reactive cells were categorized as gastrointestinal type. When MUC2 positive cells were less than HGM, MUC5AC and MUC6 reactive cells, the lesions were categorized gastric-dominant type. When MUC2 positive cells were more than HGM, MUC5AC and MUC6 reactive cells, the lesions were categorized intestinal-dominant type. CD10 and/or CDX2 positive cells were categorized as intestinal phenotype regardless of the percentages. In addition, MUC2 positive cells without MUC5AC, MUC6 and HGM expression were categorized intestinal phenotype (Fig. 2).

Evaluation of background atrophic mucosa. To investigate the relationship between early gastric cancer and the background of non-neoplastic mucosa, we evaluated three indicators of background mucosa: (a) mucosal heights, (b) the number of glands per 100 times power field and (c) the presence of intestinal metaplasia (IM) (Figs. 1A and 2A). The mucosal heights were evaluated as the average of three points which we measured in each lesion, i.e. EGC lesion and its background non-neoplastic mucosa. The evaluation of IM was according to the Updated Sydney System scores 0-3, i.e., 0, none; 1, mild; 2, moderate; and 3, severe IM (2).

Statistical analysis. The correlation between mucin phenotypes and histopathological grades was analyzed using the Pearson $\chi^{2}$ test. The nonparametric Mann-Whitney U-test was used to compare average of mucosal heights, number of glands and presence of IM with clinical characteristics. The $P$ values were two-sided, and $P$ values of $<0.05$ were considered statistically significant. We used SPSS software, version 12.0 (SPSS, Inc., Chicago, IL, USA).

\section{RESULTS}

Mucin phenotypes in gastric cancers

We performed MUC5AC, MUC6, HGM, MUC2, CD10 and CDX2 immunostaining. HGM, MUC5AC and/or MUC6 reactive neoplastic cells were categorized by gastric phenotype. CD10 and/or CDX2 positive neoplastic cells were categorized as intestinal phenotype regardless of the percentages. In addition, MUC2 reactive neoplastic cells without MUC5AC, MUC6 and HGM expression were categorized intestinal phenotype. HGM, MUC5AC, MUC6 and MUC2 reactive neoplastic cells were categorized gastrointestinal type; this type was sub-classified into gastric-dominant type (HGM, MUC5AC and MUC6 predominant staining) and intestinal-dominant type (MUC2 predominant staining).

Based on the immunohistochemical mucin phenotypes, we classified the $81 \mathrm{EGC}$ cases into the gastric type group (gastric and gastric-dominant phenotypes, 38 cases, $46.9 \%$ ) and intestinal type group (intestinal and intestinal-dominant phenotypes, 43 cases, $53.1 \%$ ); and sub-classified into the four phenotypes: gastric (21 cases, $25.9 \%$ ), gastric-dominant (17 cases, 21.0\%), intestinal-dominant (21 cases, $25.9 \%$ ), and intestinal (22 cases, $27.2 \%$ ) phenotypes. 

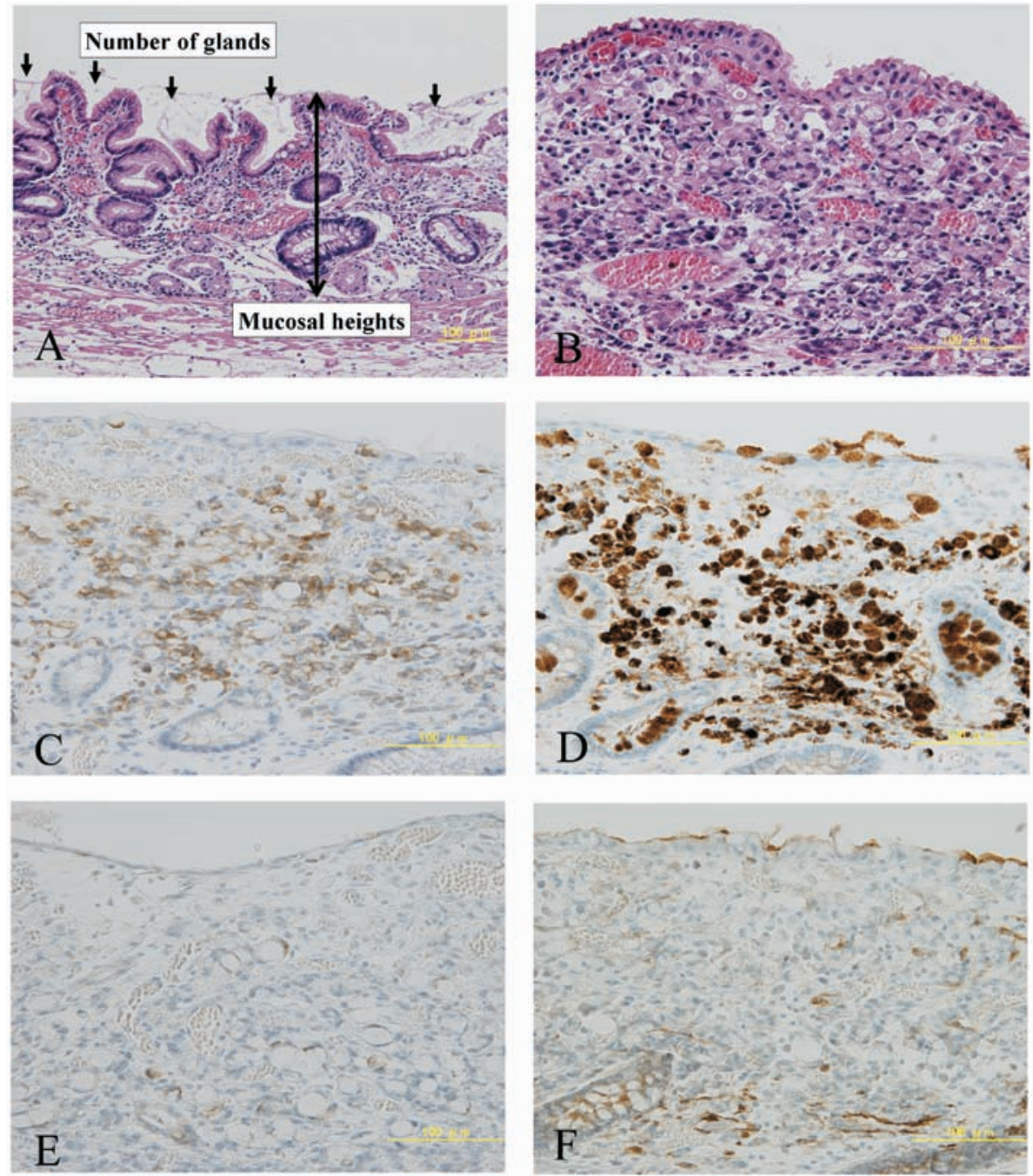

Fig. 1 A representative case of signet-ring cell carcinoma (poorly differentiated adenocarcinoma) with gastric phenotype. (A) Background gastric mucosa of adenocarcinoma, mucosal heights (350 $\mu \mathrm{m}$ in this case), number of glands (six glands in this case, arrows) and intestinal metaplasia in a moderate degree (score 2 in this case); (B) Signet-ring cell carcinoma (H\&E); (C) Positive MUC5AC expression in the cytoplasm of carcinoma cells; (D) Positive HGM expression in the cytoplasm of carcinoma cells; (E) Negative MUC2 expression; and (F) Negative CD10 expression.

$62.4 \%(34 / 53)$ of the well differentiated adenocarcinoma cases showed intestinal type group, while $67.9 \%(19 / 28)$ of the moderately to poorly differentiated adenocarcinoma cases exhibited gastric type group. Mucin phenotypes of EGC were significantly correlated with histopathological grades $(P=0.010)$ (Table 3).

Relationship between mucin phenotypes of gastric cancer and its the background mucosa

We measured the mucosal heights and the number of glands, and evaluated the scores of IM of the non-neoplastic gastric mucosa around EGC. The average scores of IM of the background mucosa were significantly associated with the macroscopic types of EGC; i.e. IM of non-neoplastic mucosa around elevated tumors (1.60 of IM score) was higher than that of depressive tumors $(0.89$ of IM score, $P=$ 0.003). The average mucosal heights around EGC were lower in moderately to poorly differentiated adenocarcinoma cases $(442.6 \mu \mathrm{m})$ than those in well differentiated adenocarcinoma cases $(500.2 \mu \mathrm{m}$, $P=0.011$ ). Based on the mucin phenotypes of EGC, the average mucosal heights were lower in the gastric type group (gastric and gastric-dominant phenotypes, $452.8 \mu \mathrm{m}$ ) than those in intestinal type group (intestinal and intestinal-dominant phenotypes, $505.6 \mu \mathrm{m}, P=0.018)$. The gastric type group was 

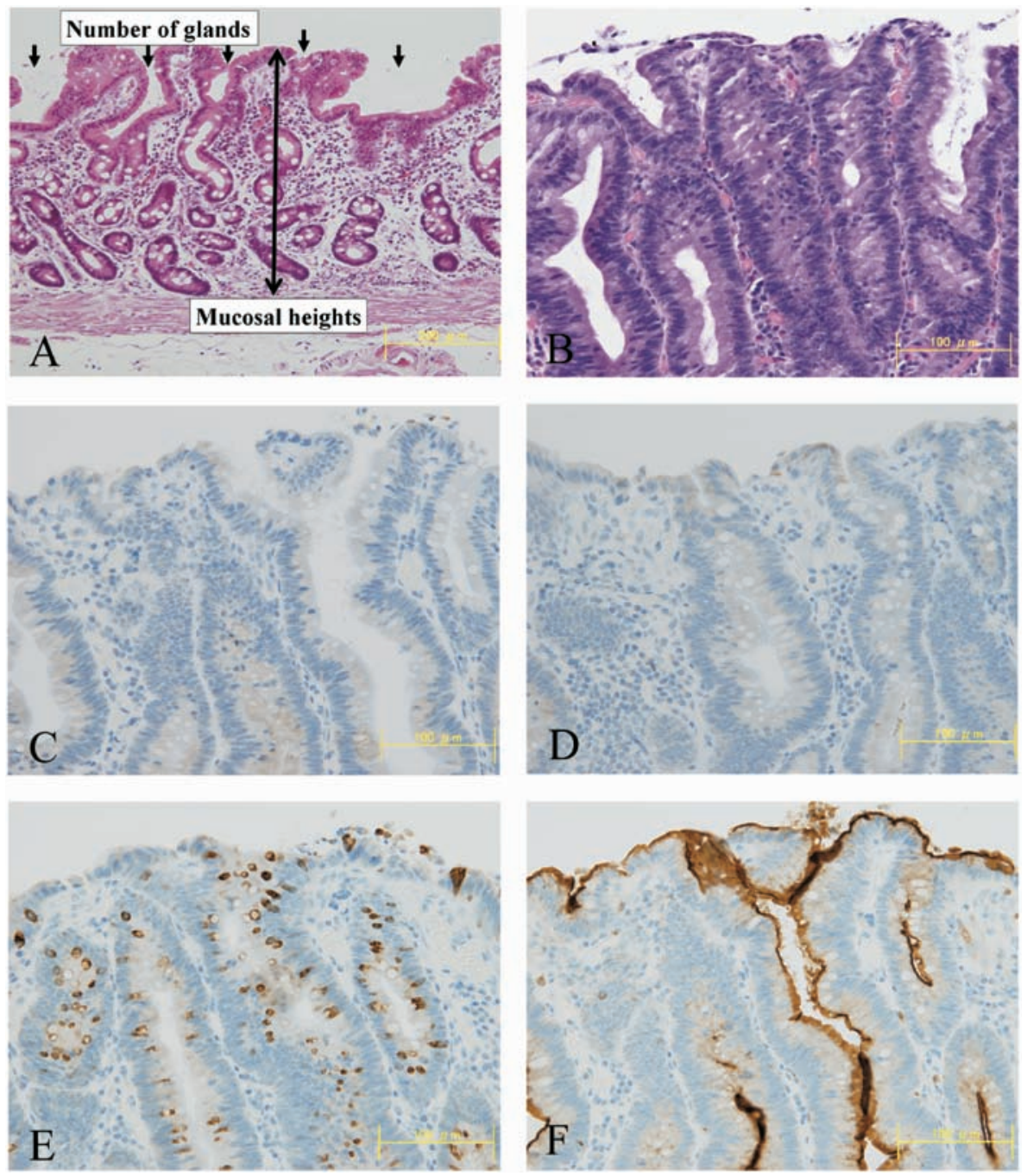

Fig. 2 A representative case of well differentiated adenocarcinoma with intestinal phenotype. (A) Background gastric mucosa of adenocarcinoma, mucosal heights $(450 \mu \mathrm{m}$ in this case), number of glands (ten glands in this case, arrows) and intestinal metaplasia in a severe degree (score 3 in this case); (B) Well differentiated adenocarcinoma (H\&E); (C) Negative MUC5AC expression; (D) Negative human gastric mucin (HGM) expression; (E) Positive MUC2 expression in the cytoplasm of neoplastic goblet cells; and s(F) Positive CD10 expression at the neoplastic brush borders.

lower in score of IM (1.15 of IM score) than that of intestinal type group (1.65 of IM score, $P=0.012$ ).

Of the 81 cases, 41 EGC cases $(50.6 \%)$ were located to the fundic gland area, 38 cases $(46.9 \%)$ in the pyloric gland area, and the other two cases $(2.5 \%)$ were in the cardiac gland area. In the fundic gland area, there was a tendency that the average mucosal heights around EGC were lower in moderately to poorly differentiated adenocarcinoma cases $(428.9 \mu \mathrm{m})$ than in well differentiated adenocarcinoma cases $(484.4 \mu \mathrm{m}, P=0.075)$ (Table 4$)$. The average scores of IM was significantly lower in moderately to poorly differentiated adenocarcinoma cases (1.29 of IM score) than in well differentiated adenocarcinoma cases $(2.00, P=0.010)$. Based on the mucin phenotypes of EGC, the average mucosal heights around EGC were lower in the gastric type group $(413.2 \mu \mathrm{m})$ than that in intestinal type group (495.5 $\mu \mathrm{m}, P=0.015)$.

In the pyloric gland area, there was a tendency that the average mucosal heights around EGC were lower in moderately to poorly differentiated adenocarcinoma cases, as well as in the gastric phenotype group (no statistical differences) (Table 4). In addition, there was a tendency that the average scores of IM were lower in the gastric type group ( 0.88 of IM score) than in the intestinal type group (1.44 of IM score, $P=0.095$ ) 
Table 3 Relationship between mucin phenotypes and histopathological grades

\begin{tabular}{|c|c|c|c|}
\hline & & \multicolumn{2}{|c|}{ Histopathological grade } \\
\hline & & $\begin{array}{l}\text { Well differentiated } \\
\qquad(\mathrm{n}=53)\end{array}$ & $\begin{array}{l}\text { Moderately to poorly } \\
\text { differentiated } \\
(\mathrm{n}=28)\end{array}$ \\
\hline \multicolumn{4}{|l|}{ Mucin phenotype of early gastric cancer } \\
\hline Gastric phenotype $(\mathrm{n}=21)$ & \multirow{2}{*}{$\begin{array}{l}\text { Gastric type } \\
\text { group }\end{array}$} & 11 & 10 \\
\hline $\begin{array}{l}\text { Gastric-dominant gastrointestinal } \\
\text { phenotype }(n=17)\end{array}$ & & 8 & 9 \\
\hline $\begin{array}{l}\text { Intestinal-dominant gastrointestinal } \\
\text { phenotype }(\mathrm{n}=21)\end{array}$ & \multirow{2}{*}{$\begin{array}{l}\text { Intestinal type } \\
\text { group }\end{array}$} & 18 & 3 \\
\hline Intestinal phenotype $(\mathrm{n}=22)$ & & 16 & 6 \\
\hline
\end{tabular}

Table 4 Histological phenotypes of early gastric cancer (EGC) and its background mucosa

\begin{tabular}{|c|c|c|c|c|c|c|}
\hline & \multicolumn{6}{|c|}{ Background non-neoplastic mucosa } \\
\hline & $\begin{array}{l}\text { Mucosal } \\
\text { heights } \\
\text { (mean } \pm \text { s.d.) }\end{array}$ & $P$ value & $\begin{array}{l}\text { Number of } \\
\text { glands } \\
\text { (mean } \pm \text { s.d.) }\end{array}$ & $P$ value & $\begin{array}{c}\text { Degree of } \\
\text { IM } \\
\text { (mean } \pm \text { s.d.) }\end{array}$ & $P$ value \\
\hline \multicolumn{7}{|l|}{ Total $(\mathrm{n}=81)$} \\
\hline \multicolumn{7}{|l|}{ Macroscopic type of EGC } \\
\hline Elevated $(n=59)$ & $482.7 \pm 118.2$ & 0.924 & $10.2 \pm 1.8$ & 0.165 & $1.60 \pm 0.86$ & 0.003 \\
\hline Depressive $(n=22)$ & $473.9 \pm 74.3$ & & $10.9 \pm 1.8$ & & $0.89 \pm 0.92$ & \\
\hline \multicolumn{7}{|l|}{ Histopathological grade of EGC } \\
\hline Well differentiated $(n=53)$ & $500.2 \pm 111.4$ & 0.011 & $10.6 \pm 1.9$ & 0.141 & $1.49 \pm 0.99$ & 0.255 \\
\hline Moderate to poorly differentiated $(n=28)$ & $442.6 \pm 90.6$ & & $10.0 \pm 1.7$ & & $1.26 \pm 0.79$ & \\
\hline \multicolumn{7}{|l|}{ Mucin phenotype of EGC } \\
\hline Intestinal type $(n=43)$ & $505.6 \pm 107.2$ & 0.018 & $10.4 \pm 1.9$ & 0.744 & $1.65 \pm 0.95$ & 0.012 \\
\hline Gastric type $(n=38)$ & $452.8 \pm 102.6$ & & $10.4 \pm 1.8$ & & $1.15 \pm 0.82$ & \\
\hline \multicolumn{7}{|l|}{ Fundic glands area $(\mathrm{n}=41)$} \\
\hline \multicolumn{7}{|l|}{ Macroscopic type of EGC } \\
\hline Elevated $(n=35)$ & $465.0 \pm 110.5$ & 0.733 & $10.1 \pm 1.8$ & 0.872 & $1.83 \pm 0.77$ & 0.067 \\
\hline Depressive $(n=6)$ & $440.3 \pm 91.4$ & & $10.3 \pm 2.0$ & & $1.00 \pm 1.10$ & \\
\hline \multicolumn{7}{|l|}{ Histopathological grade of EGC } \\
\hline Well differentiated $(n=24)$ & $484.4 \pm 112.6$ & 0.075 & $10.2 \pm 2.0$ & 0.499 & $2.00 \pm 0.79$ & 0.01 \\
\hline Moderate to poorly differentiated $(n=17)$ & $428.9 \pm 92.9$ & & $10.0 \pm 1.7$ & & $1.29 \pm 0.81$ & \\
\hline \multicolumn{7}{|l|}{ Mucin phenotype of EGC } \\
\hline Intestinal type $(n=24)$ & $495.5 \pm 117.4$ & 0.015 & $10.2 \pm 1.8$ & 0.894 & $1.86 \pm 0.89$ & 0.15 \\
\hline Gastric type $(n=17)$ & $413.2 \pm 68.9$ & & $10.0 \pm 2.0$ & & $1.49 \pm 0.80$ & \\
\hline \multicolumn{7}{|l|}{ Pyloric glands area $(\mathrm{n}=38)$} \\
\hline \multicolumn{7}{|l|}{ Macroscopic type of EGC } \\
\hline Elevated $(n=22)$ & $508.3 \pm 129.7$ & 0.849 & $10.6 \pm 1.7$ & 0.258 & $1.30 \pm 0.93$ & 0.145 \\
\hline Depressive $(\mathrm{n}=16)$ & $486.5 \pm 65.9$ & & $11.2 \pm 1.7$ & & $0.85 \pm 0.88$ & \\
\hline \multicolumn{7}{|l|}{ Histopathological grade of EGC } \\
\hline Well differentiated $(\mathrm{n}=28)$ & $510.1 \pm 111.4$ & 0.317 & $11.0 \pm 1.7$ & 0.272 & $1.07 \pm 0.96$ & 0.732 \\
\hline Moderate to poorly differentiated $(n=10)$ & $468.3 \pm 90.6$ & & $10.4 \pm 1.7$ & & $1.23 \pm 0.85$ & \\
\hline \multicolumn{7}{|l|}{ Mucin phenotype of EGC } \\
\hline Intestinal type $(\mathrm{n}=17)$ & $520.8 \pm 94.0$ & 0.234 & $11.0 \pm 1.8$ & 0.759 & $1.44 \pm 1.05$ & 0.095 \\
\hline Gastric type $(n=21)$ & $483.3 \pm 114.9$ & & $10.7 \pm 1.6$ & & $0.88 \pm 0.77$ & \\
\hline
\end{tabular}




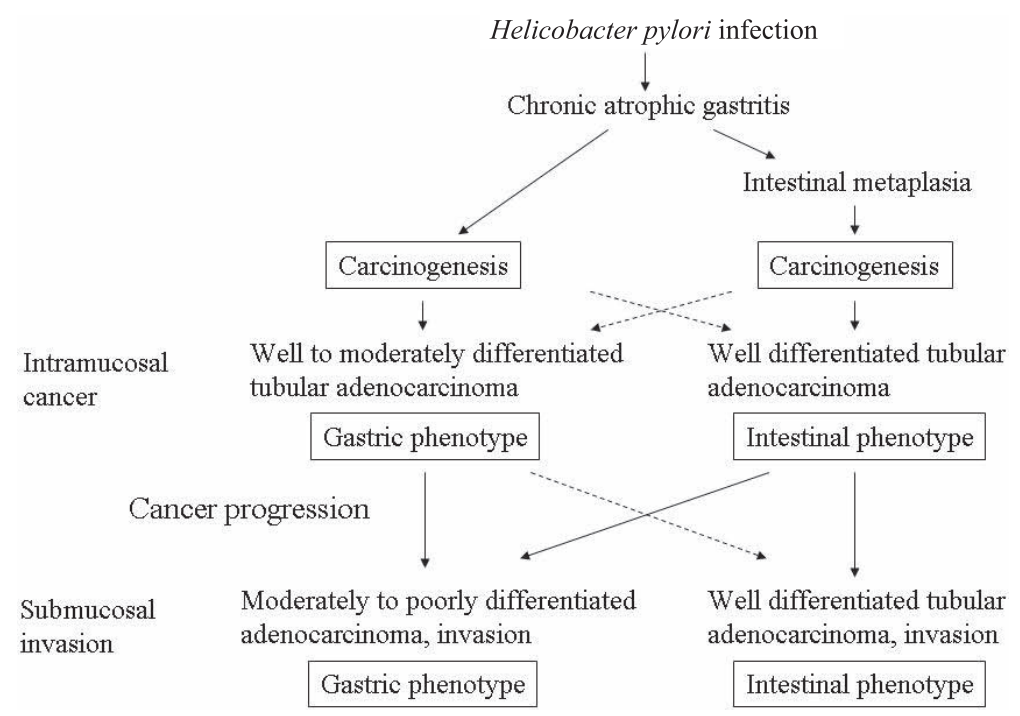

Fig. 3 Hypothesis of gastric carcinogenesis and progression

\section{DISCUSSION}

The risk of gastric cancer is related to Helicobacter pylori infection with chronic active inflammation. Previous studies have described the association between EGC and IM. However, relationships between EGC and gastric atrophy are not well understood. In this study, we demonstrated that the cases of moderately to poorly differentiated adenocarcinoma, as well as gastric-type EGC, were more closely associated with atrophy.

The most cases of gastric differentiated adenocarcinoma have been considered to show intestinal phenotypes, and histogenesis of the differentiated adenocarcinoma is related to $\operatorname{IM}(3,7,11)$. On the other hand, several papers have reported that some differentiated adenocarcinoma expressed gastric phenotypes (5). In addition, small-sized differentiated adenocarcinoma with gastric mucin expression may develop into large poorly differentiated adenocarcinoma (commonly called undifferentiated carcinoma) during the tumor progression of EGC $(3,10,13,16$, $21)$. These reports indicated that the mucin phenotypes were associated with histopathological differentiation of EGC frequently (9), but not completely. Our results supported this tendency, and showed that $67.9 \%$ of moderately to poorly differentiated adenocarcinoma cases were gastric type group, while $64.2 \%$ of well differentiated adenocarcinoma cases were intestinal type group.

Gastric mucosa is frequently infected with Helicobacter pylori, which cause chronic inflammatory cell infiltration. The persistent inflammatory stimula- tion injuries the gastric mucosa, and reduces the proper gastric glands, i.e. atrophy. The injured mucosa regenerates another type of epithelium, i.e. socalled IM. Therefore, Helicobacter pylori infection results in atrophic gastritis including IM (6). Helicobacter pylori infection and severe chronic gastritis with IM are thought to become high risks for differentiated adenocarcinoma in EGC. It has been shown that differentiated adenocarcinoma appears in the mucosa with severe atrophic gastritis and significant IM (1, 22). In contrast, undifferentiated carcinoma (actually poorly differentiated adenocarcinoma and/ or signet-ring cell carcinoma) arises during progression of atrophic gastritis with Helicobacter pylori infection regardless of IM $(18,22)$. Undifferentiated carcinoma is shown to originate not only from IM, but also from the gastric proper mucosa without IM (5). The relationship between atrophic gastritis and undifferentiated carcinoma has not yet been understood. Therefore, we evaluated the background of gastric mucosa using three evaluation criteria, i.e. mucosal heights, number of glands and score of IM, and discussed the relationship between EGC and atrophic gastric mucosa.

As shown our results, the background gastric mucosa with lower IM score was related to the gastric phenotype cancers, and atrophic mucosa with lower mucosal heights was associated with moderately to poorly differentiated adenocarcinoma. We speculated that moderately to poorly differentiated type of EGC originates from the atrophic gastric mucosa with lower mucosal heights and less IM, and has mucin expression of the gastric phenotype. This type of 
EGC is thought to develop to poorly differentiated gastric phenotype (commonly called "undifferentiated carcinoma”) in advanced cases (Fig. 3).

In conclusion, our data suggest that gastric phenotype group cancer and moderately to poorly differentiated adenocarcinoma tended to have background atrophic mucosa with low mucosal heights and less IM. The atrophic gastric mucosa with less IM is thought to play an important role in gastric carcinogenesis, especially tumoriogenesis of gastric phenotype group cancer and moderately to poorly differentiated adenocarcinoma.

\section{Acknowledgements}

This study was supported by Grants-in-Aid for Science from the Ministry of Education, Culture Sports, Science, and Technology of Japan; Grant for Hirosaki University Institutional Research; and the Karoji Memorial Fund for Medical Research.

\section{REFERENCE}

1. Correa P (1992) Human gastric carcinogenesis: A multistep and multifactorial process. First American Cancer Society Award Lecture on Cancer Epidemiology and Prevention. Cancer Res 52, 6735-6740.

2. Dixon MF, Genta RM, Yardley JH, Correa P and the participants in the Intetnational Workshop on the Histopathology of Gastritis, Houston 1994 (1996) Classification and grading of gastritis. Am J Surg Pathol 20, 1161-1181.

3. Egashira Y, Shimoda T and Ikegami M (1999) Mucin histochemical analysis of minute gastric differentiated adenocarcinoma. Pathol Int 49, 55-61.

4. Japanese Gastric Cancer Association (1999) Japanese Classification of Gastric Carcinoma, 13th ed., Kanehira, Tokyo.

5. Kabashima A, Yao T, Maehara Y and Tsuneyoshi M (2005) Relationship between biological behavior and phenotypic expression in undifferentiated-type gastric carcinomas. Gastric Cancer 8, 220-227.

6. Kudo Y, Tsutsumi S, Hara S, Akasaka H, Jin H, Morohashi S, Sato F, Hanabata N, Yoshimura T, Fukuda S and Kijima H (2009) Chronic atrophic gastritis as background of early gastric cancer. Stomach and Intestine 44, 1412-1422. (in Japanese with English abstract)

7. Lauren $P$ (1965) The two histological main types of gastric carcinoma: diffuse and so-called intestinal-type carcinoma. Acta Pathol Microbiol Scand 64, 31-49.

8. Lawrence M and Shiu MH (1991) Early gastric cancer: twenty-eight year experience. Ann Surg 213, 327-334.

9. Lee OJ, Kim HJ, Kim JR and Watanabe H (2009) The prognostic significance of the mucin phenotype of gastric adenocarcinoma and its relationship with histologic classification.
Oncol Rep 21, 387-393.

10. Mizoshita T, Tsukamoto T, Inada K, Ogasawara N, Hirata A, Kato S, Joh T, Itoh M, Yamamura Y and Tatematsu M (2004) Immunohistochemically detectable $\mathrm{Cdx} 2$ is present in intestinal phenotypic elements in early gastric cancers of both differentiated and undifferentiated types, with no correlation to non-neoplastic surrounding mucosa. Pathol Int 54, 392-400.

11. Nakamura K, Sugano H and Takagi K (1968) Carcinoma of the stomach in incipient phase: its histologenesis and histological appearances. Gann 59, 251-258.

12. Ohta H, Noguchi Y, Takagi K, Nishi M Kajitani T and Kato Y (1987) Early gastric carcinoma with special reference to macroscopic classification. Cancer 60, 1099-1106.

13. Saito A, Shimoda T, Nakanishi Y, Ochiai A and Toda G (2010) Histologic heterogeneity and mucin phenotypic expression in early gastric cancer. Pathol Int 51, 165-171.

14. Sasaki I, Yao T, Nawata H and Tsuneyoshi M (1999) Minute gastric carcinoma of differentiated type with special reference to the significance of intestinal metaplasia, proliferative zone, and p53 protein during tumor development. Cancer 85, 1719-1729.

15. Shiotani A, Kamada T, Yamanaka Y, Manabe N, Kusunoki H, Hata J and Haruma K (2008) Sonic hedgehog and CDX2 expression in the stomach. $J$ Gastroenterol Hepatol 23, S161S166.

16. Shiroshita H, Watanabe H, Ajioka Y, Watanabe G, Nishikura K and Kitano S (2004) Re-evaluation of mucin phenotypes of gastric minute well differentiated-type adenocarcinomas using a series of HGM, MUC5AC, MUC6, M-GCMC, MUC2 and CD10 stains. Pathol Int 54, 311-321.

17. Sipponen P and Kimura K (1994) Intestinal metaplasia, atrophic gastritis and stomach cancer: trends over time. Eur $J$ Gastroenterol Hepatol 6, S79-83.

18. Sipponen P, Kosunen TU, Valle J, Riihela M and Seppala K (1992) Helicobacter pylori infection and chronic gastritis in gastric cancer. J Clin Pathol 45, 319-323.

19. Tahara E, Senba S and Tahara H (1996) Molecular biological observations in gastric cancer. Semin Oncol 23, 307-315.

20. Tajima Y, Yamazaki K, Makino R, Nishino N, Aoki S, Kato M, Morohara K, Kaetsu T and Kusano M (2006) Gastric and intestinal phenotypic marker expression in early differentiated type tumors of the stomach: clinicopathologic significance and genetic background. Clin Cancer Res 21, 6460-6479.

21. Takahashi H, Endo T, Yanashita K, Arimura Y, Yamamoto H, Sasaki S, Itoh F, Hirata K, Imamura A, Kondo M, Sato T and Imai K (2002) Mucin phenotype and microsatellite instability in early multiple gastric cancers. Int $J$ Cancer 100, 419-424.

22. Uemura N, Okamoto S, Yamamoto S, Matsumura N, Yamaguchi S, Yamakido M, Taniyama K, Sasaki N and Schlemper RJ (2001) Helicobacter pylori infection and the development of gastric cancer. $N$ Engl J Med 345, 784-789.

23. Wakatsuki K, Yamada Y, Narikiyo M, UENO M, Takayama T, Tamaki H, Miki K, Matsumoto S, Enomoto K, Yokotani T and Nakajima Y (2008) Clinicopathological and prognostic significance of mucin phenotype in gastric cancer. J Surg Oncol 98, 124-129. 